Rabaska

Revue d'ethnologie de l'Amérique française

\title{
Pierre Lessard (1950-2011)
}

\section{Michel Lessard}

Volume 9, 2011

URI : https://id.erudit.org/iderudit/1005912ar

DOI : https://doi.org/10.7202/1005912ar

Aller au sommaire du numéro

Éditeur(s)

Société québécoise d'ethnologie

ISSN

1703-7433 (imprimé)

1916-7350 (numérique)

Découvrir la revue

Citer ce document

Lessard, M. (2011). Pierre Lessard (1950-2011). Rabaska, 9, 245-246.

https://doi.org/10.7202/1005912ar

Ce document est protégé par la loi sur le droit d'auteur. L'utilisation des services d'Érudit (y compris la reproduction) est assujettie à sa politique d'utilisation que vous pouvez consulter en ligne.

https://apropos.erudit.org/fr/usagers/politique-dutilisation/ 


\section{Pierre Lessard (1950-2011)}

Pierre Lessard est décédé à Québec le 4 mars 2011 à l'âge de 60 ans et 11 mois. Il laisse dans le deuil son épouse, Jocelyne Mathieu, professeur d'ethnologie des francophones en Amérique du Nord à l'Université Laval, et ses deux filles, Joëlle et Jeanne. En 1979, il obtenait une maîtrise en ethnographie traditionnelle de l'Université Laval préparée sous la direction de Jean Simard. Peu après, il publiait Les Petites Images dévotes. Leur utilisation traditionnelle au Québec (Québec, Les Presses de l'Université Laval, « Ethnologie de l'Amérique française », 1981, 174 p.). Il a également écrit des articles sur la thématique de la religion populaire, dont «L'Imagerie religieuse », dans Jean Simard, en collaboration

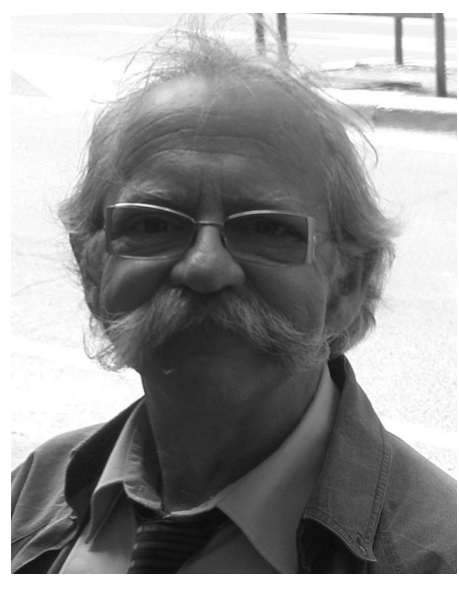
avec Jocelyne Milot et René Bouchard, Un patrimoine méprisé. La religion populaire des Québécois (Cité de LaSalle, Hurtubise HMH «Cahiers du Québec », 1979, p. 175-193) ; "L'Intérieur domestique rural », dans Le Grand héritage. L'Église catholique et les arts au Québec (Québec, Musée du Québec, 1984, p. 293-309). Pierre Lessard a fait carrière à Parcs Canada à titre de réalisateur en interprétation.

\section{Une âme en bouteille}

Pour moi, Pierre était un éblouissement. Il incarnait dans sa personne et son discours la surprise et l'émerveillement. Pierre était un poète de l'objet et de la culture matérielle populaire. Pour moi qui suis très physiognomoniste (le terme est très français), Pierre était très Lessard et très Beauceron. Imprégné ! Il embrassait fort et grand. J'aimais le voir s'allumer derrière sa grosse moustache en broussaille, les yeux pétillants et un visage narquois parler d'un saint Isidore sorti du cœur d'un habitant, d'un calvaire en bouteille né 
de la patience d'un retraité de village, d'un bouquet éternel de fleurs de bois polychrome et de broche, et encore, et encore. Pierre portait dans son âme l'imaginaire et le rêve du petit monde de tout un peuple, avec science et sensibilité. Pierre était pour moi une souris grise en promenade dans la forêt enchantée à effeuiller la terre pour rédiger un long poème parlant de comètes, d'étoiles à huit branches, de cœurs saignants, de trèfles à quatre feuilles, un arc-en-ciel de fantaisie et de bonheur souriant qu'il était toujours prêt à partager avec celui ou celle qu'il rencontrait par hasard et qu'il aimait.

Qu'il repose en paix cet homme de sens, au grand jardin du sens. 